\title{
O papel do SEBRAE na disseminação da Educação Empreendedora na região Noroeste de Minas Gerais
}

\author{
Amanda Caroline Farias ALVES \\ Faculdade CNEC Unaí, Unaí, MG, Brasil \\ Gevair CAMPOS \\ Faculdade CNEC Unaí, Unaí, MG, Brasil
}

\author{
Received 8 fev. 19; Accepted 7 Mai. 19 \\ Evaluation System: Double Blind Review \\ Editor: Jose Lindenberg Julião Xavier Filho, Dr. \\ ISSN: $2594-8040$
}

To cite this paper: Alves, A. C. F. \& Campos, G. (2019). O papel do SEBRAE na disseminação da Educação Empreendedora na região noroeste de Minas Gerais. Journal of Perspectives in Management - JPM, 3(2), p. 2-20.

\section{Resumo}

Este estudo tem como objetivo evidenciar o papel do Programa de Educação Empreendedora do SEBRAE, bem como seus pontos positivos, ressaltando a necessidade da ascensão desse tipo de educação para o crescimento econômico, social e sustentável. Essa pesquisa foi delimitada na Regional Noroeste de Minas, através da análise do Radar da Educação Empreendedora para Instituições de Ensino, uma ferramenta com atributos que permite apurar o grau de implementação do Programa, sendo assim foram disponibilizadas três devolutivas de escolas das cidades de Arinos, Paracatu e Unaí dos três tipos de graus de implementação, sendo eles alto, médio e baixo com o intuito de se analisar os diferentes tipos. A pesquisa é classificada como bibliográfica, de abordagem qualitativa, com finalidade explicativa e de instrumento documental. Os dados foram analisados através da análise de conteúdo. A relevância dos resultados está nas ações de cada dimensão formando o ecossistema de Educação Empreendedora e o engajamento de todos. Na dimensão atores evidencia a importância do papel do professor como um dos principais agentes de transformação. Ressalta também a participação da escola como apoiadora, sustentadora e incentivadora desse programa. Os recursos e estruturas também influenciam diretamente a implementação do ecossistema empreendedor nas escolas. O SEBRAE na capacitação dos agentes envolvidos no programa exerce seu papel como agente de transformação na disseminação da Cultura Empreendedora e seus resultados positivos, ressaltando os caminhos para a manutenção do programa.

Palavras-Chave: Educação Empreendedora; SEBRAE; Empreendedorismo. 


\section{Introdução}

A situação econômica do Brasil sofre constantes mudanças provocando consecutivas transformações empresariais e sociais em todas as regiões do país. Com a modernidade dos tempos e a crise, o meio em que vivemos busca o capital humano daqueles que possuem competências múltiplas, rápida adaptação de ambiente, trabalho e estilo de vida flexíveis, que identifiquem novos desafios, estejam atentos às transformações e que saibam identificar oportunidades no mercado.

Segundo Ângelo (2003), o ambiente empresarial cada vez mais exige pessoas que estão devidamente qualificadas, consideradas inovadoras e criativas. Nesse perfil, o empreendedorismo vem ganhando um amplo espaço como modo de vida, em que a iniciativa de transformação da oportunidade faz a diferença. O empreendedorismo no Brasil cresce estreitamente nos últimos anos. A crise, o desemprego, a vontade de ser ator principal da sua própria história e a realização de ter o seu próprio negócio são fatores que contribuem para esse crescimento.

Segundo Baggio \& Baggio (2014, p.27) "o empreendedor tem iniciativa para criar um negócio e paixão pelo que faz [...] é receptivo às oportunidades e aceita assumir riscos [...]" Nesta perspectiva, como fomentador deste movimento no Brasil, o Serviço Brasileiro de Apoio às Micro e Pequenas Empresas (SEBRAE) vem transformando muitas vidas com empreendedorismo nas escolas. Ele ajuda o estudante a enxergar e avaliar determinada situação, sendo proativo a ela, capacitando-o a elaborar e planejar formas e estratégias de interagir com o que ele passou a perceber. O SEBRAE tem um papel importante nesse assunto, por meio do desenvolvimento do Programa de Educação Empreendedora, que dissemina a cultura empreendedora nas escolas (SEBRAE Minas, 2017a).

O SEBRAE é uma entidade privada sem fins lucrativos. É um agente de capacitação e de promoção do desenvolvimento, criado para dar apoio aos pequenos negócios de todo o país. Desde 1972, trabalha para estimular o empreendedorismo e possibilitar a competitividade e a sustentabilidade dos empreendimentos de micro e pequeno porte (SEBRAE Nacional, 2018a, online).

Existem inúmeras razões para a capacitação dessas escolas em relação a disciplina e conteúdo de empreendedorismo e uma delas é o incentivo imediato para empreender. Diante do exposto, emerge a seguinte questão de pesquisa: O que o Programa de Educação Empreendedora do SEBRAE Minas tem feito que agregue valor para a educação da Regional Noroeste de Minas?

Portanto esse artigo tem como objetivo geral evidenciar o papel do Programa de Educação Empreendedora do SEBRAE Minas, bem como seus efeitos positivos, ressaltando a necessidade da ascensão desse tipo de educação para o crescimento econômico, social e sustentável. Para alcançar o objetivo da pesquisa busca levantar a importância do papel do educador juntamente com a escola e as dimensões nessa trajetória de ensino aprendizagem intensificando a seriedade desse programa específico trabalhado pelo SEBRAE Minas.

Nessa medida este trabalho se justifica por apresentar a efetividade e os casos inspiradores apresentados, destacando a importância desse assunto por ser de cunho educacional e de grande potencial de transformação para o futuro. Segundo SEBRAE Nacional (2017b) a Educação Empreendedora propõe a ruptura de um modelo de prática educacional que privilegia a transmissão estática e a crítica de dados e informações sem estimular reflexões ou a aplicação dos saberes na forma de ações transformadoras. Nesta perspectiva o mesmo autor ressalta que não basta ensinar conteúdos técnicos ou apresentar ao estudante os muitos dilemas e desafios de nossa sociedade, estimulando-o a pensar caminhos de mudança. É necessário, efetivamente, capacitá-lo a construir esses caminhos por meio de ações concretas e tecnicamente embasadas que tenham efetiva capacidade transformadora e, sobretudo, o levem a aliar a teoria à prática.

Baggio \& Baggio (2019) ressaltam que não haverá desenvolvimento econômico sem que na sua base existam líderes empreendedores. Assim, evidencia a importância da Educação 
Empreendedora, pois os futuros donos dos seus próprios negócios podem se originar dentro das escolas e amadurecerem essas ideias, e assim contribuir para o desenvolvimento local, regional, nacional e até a nível global.

O presente artigo está estruturado da seguinte forma: a seção 2 trata-se de uma abordagem geral e conceitual sobre cultura empreendedora do SEBRAE, tipos de empreendedorismo e caso de sucesso da região; a seção 3 aborda a metodologia empregada para responder à questão da pesquisa proposta; a seção 4 apresenta os resultados e discussões sobre as devolutivas dos radares aplicados e seus respectivos resultados proporcionados por uma análise realizada pelo SEBRAE; a seção 5 traz as considerações finais e por fim as referências utilizadas para dar ênfase, complemento e base nos estudos.

\section{Educação e Educador}

Disseminar a educação é um desafio grande que requer cautela para usufruir de bons resultados, no que tange um país como o Brasil, que possui um desenvolvimento baixo em educação, isso se torna mais distante ainda da realidade que se pretende alcançar, o empreendedorismo corresponde às mudanças e sabe-se que toda mudança requer tempo.

A prática do empreendedorismo vem ganhando forças com a metodologia do "Programa Cultura Empreendedora oferecendo práticas pedagógicas inovadoras para que o educador possa desenvolver e aprimorar as competências empreendedoras nos alunos" (SEBRAE Minas, 2017a, on-line).

Na compreensão de Roese, Binoto \& Bullau (2005), ninguém nasce empreendedor, mas as características empreendedoras podem ser desenvolvidas ao longo de sua carreira profissional, preparando para assumir riscos ou desafios em um novo empreendimento, a cultura e influência do ambiente criam a paixão.

Várias são as características do empreendedor segundo Dolabela (1999a) denomina o empreendedor é alguém que tem visão e sabe induzir sócios, investidores, colaboradores e terceiros a apostar na sua ideia. $\mathrm{O}$ autor atribui a ele a capacidade de identificar as oportunidades e buscar os recursos para transformá-las em negócios lucrativos.

Segundo Thiago Chaer (2018), co-fundador da organização Future Education, primeira organização latino-americana focada no desenvolvimento de startups de educação, o que se esperar da demanda da nova geração de alunos para educação. Segundo o autor os alunos querem muita prática... querem se sentir protagonistas... se esses jovens não encontram essa mesma liberdade em sala de aula, ficam frustrados... (Chaer, 2018, on-line). Como o autor menciona, o modelo de aprendizagem precisa também inovar e alinhar ao novo modelo da geração, geração de potencial, de prática e de acesso às informações constantemente.

O leque da educação abre fronteiras em diversos aspectos como pessoal, intelectual e também profissional. Assim, ela cria um laço importante com o empreendedorismo sendo uma base de conhecimentos adquiridos ainda na infância e adolescência para que posteriormente sejam transformados em práticas empreendedoras. A educação deve preparar os alunos para o futuro para que possam evoluir com a educação, e, conhecendo o mercado, possam se proteger da crise econômica no país e do desemprego.

Para a analista da área de Educação do SEBRAE-MG, Cacilda Almeida o objetivo é estimular os educadores, e consequentemente, os educandos a pensar e agir de modo empreendedor, envolvendo-os, de forma prática e vivencial, por meio de atividades lúdicas, promovidas em sala de aula (Almeida, 2012, apud SEBRAE Minas, 2012b). 
O papel do educador nessa caminhada é primordial, ele é o primeiro na disseminação do conhecimento adquirido, é ídolo para muitas crianças, consegue criar em sala de aula um ambiente interativo, interessante e desenvolvedor, mesmo que o presente que estamos vivendo seja de muita violência e dificuldades em escolas, ainda assim o educador não perdeu sua essência. $\mathrm{O}$ ambiente em que este professor está inserido é capaz de estimular as crianças a novas ideias e esse papel é muito importante, pois ele estimula o estudante a pensar e agir para seu futuro e do país, e principalmente, ele é agente de transformação.

O empreendedorismo pode surgir em várias etapas da vida de uma pessoa, não necessariamente aquele estudante que aprendeu e cresceu naquele ambiente será um empreendedor no futuro, porém esse ambiente propiciará a ele um aprendizado não só do empreendedorismo, mas sim, de finanças, cooperação, de parceria e ações que irão fazer a diferença no futuro dessa criança ou jovem. Ele será um executor do futuro, vai aprender com erros, saber lidar com frustrações, estar em um ambiente de inovação, coletivismo, engajamento, comprometimento com a causa e sem dúvidas será um cidadão melhor. Com a incerteza da economia brasileira, terá ciência inicial para lidar com sua gestão financeira, estando preparando para situações posteriores e controles pessoais e profissionais.

O SEBRAE é, indubitavelmente, um especialista em empreender para crescer, formando novas cidades, que formam novos estados e que consequentemente impulsionam o país. Ou seja, esse é o processo, o passo a passo para se chegar a um bom resultado e necessita muito das partes integrantes para se chegar ao todo. Ele possibilita ao professor estar em contato com técnicas e ferramentas de aprendizagem se tornando um agente de transformação. Assim, percebe-se que o papel do professor nessa educação é desafiador e suas ações geram resultados positivos e satisfatórios.

\subsection{SEBRAE e Educação Empreendedora}

O SEBRAE possui uma unidade central, o SEBRAE Nacional, e as demais unidades distribuídas nas capitais e regiões dos estados que trabalham em conjunto com parceiros para melhor atender os empreendedores. Especialista em pequenos negócios tem como missão promover a competitividade e o desenvolvimento sustentável dos pequenos negócios e estimular o empreendedorismo e como visão ter excelência no desenvolvimento dos pequenos negócios, contribuem para a construção de um país mais justo, competitivo e sustentável (SEBRAE Nacional, 2018b, on-line).

Nesse contexto, destaca-se o papel do SEBRAE de gerar, na educação, as condições para empreender, desenvolvendo habilidades para estimular o empreendedorismo e suas oportunidades, ainda para executar as ideias.

De acordo com o SEBRAE Minas (2017c, on-line),

O Programa Educação Empreendedora SEBRAE Minas tem como objetivo ampliar, promover e disseminar a educação empreendedora nas instituições de ensino fundamental, médio, técnico e superior de Minas Gerais, formando professores e despertando a comunidade escolar para novas possibilidades no processo de aprendizagem.

No Brasil, com os reforços das políticas públicas instauradas que apoiam o empreendedor nascente, espera-se que estes empreendedores se unam com os empreendedores que estão no mercado há mais tempo e juntos produzam, uma intensa riqueza, movimentando a economia e transformando o Brasil em uma nação desenvolvida (Machado, Felix, Greco, Bastos Junior, Silvestre, Moraes, Côrtes, \& Friedlaender Junior, 2010). 
As características do empreendedor são inúmeras e variam de acordo com o seu perfil e habilidades, é focado nos seus objetivos, faz análise de riscos ou corre risco moderados, toma decisões, planeja, trabalha em equipe, buscando sempre soluções, qualidade e eficiência no que faz com autoconfiança e capacidade de persuasão para lidar com os fornecedores (Melo, 2008, p. 1).

O empreendedor deve estar apto a mudanças, gostar de melhorar e buscar isso como forma de inovação no seu empreendimento. O SEBRAE tem papel relevante em várias ações direcionadas para o empreendedor. A educação empreendedora é uma ação que equivale a uma parte do todo, ela por si só, representa muitos resultados admiráveis, cria a cultura empreendedora dentro da instituição como forma de procriar empreendedores, que sejam inovadores e buscadores de tendências, que se tornem casos de sucesso para inspirações futuras.

Portanto para o SEBRAE Nacional (2017a, on-line) “... não se trata apenas de abrir um novo negócio, como muita gente imagina. É um novo modo de pensar, uma competência que pode ser desenvolvida." Por isso, a missão da Educação Empreendedora é desenvolver pessoas para o empoderamento. Esse empoderamento que o SEBRAE menciona traz uma conscientização coletiva que agrega mais envolvidos no programa, cria uma conscientização para a solução de problemas futuros e ajuda no crescimento dos atores para a transformação dos impasses em resultados efetivos. O SEBRAE tem todo um acompanhamento do empreendedor, desde a educação iniciante até apoio para a gestão desses futuros empreendedores, incentivando o desenvolvimento do comportamento empreendedor.

\subsection{Programa Nacional de Educação Empreendedora (PNEE) do SEBRAE}

A educação abre novos horizontes para estudantes, transmite os conhecimentos de professores para alunos, estimulando o crescimento pessoal e profissional de cada um para enxergar as oportunidades futuras. Para potencializar as ações empreendedoras o Sebre criou o Programa Nacional de Educação Empreendedora (PNEE). "O PNEE foi criado para consolidar uma atuação sistemática e organizada de ações de educação empreendedora do Sistema SEBRAE junto aos potenciais empreendedores estudantes de todo país" (SEBRAE Nacional, 2018c, on-line). O Programa atua em instituições de ensino públicas ou privadas do ensino fundamental, médio, técnico e superior com objetivo de inserir novos empreendedores no mercado de trabalho futuro, oferecendo na carga horária dos estudantes o ensino da cultura empreendedora. As dissoluções oferecidas estão descritas no quadro 1.

Quadro 1: Soluções do Programa

\begin{tabular}{|c|c|}
\hline Nível & Módulo \\
\hline Fundamental & $\begin{array}{c}\text { Jovens Empreendedores Primeiros } \\
\text { Passos } \\
\end{array}$ \\
\hline Médio & $\begin{array}{c}\quad \text { Crescendo e Empreendendo } \\
\text { Despertar } \\
\text { Formação de Jovens Empreendedores }\end{array}$ \\
\hline Profissional & Disciplina de Empreendedorismo \\
\hline Superior & $\begin{array}{l}\text { Disciplina de Empreendedorismo } \\
\text { Edital para Instituiç̃ões do Ensino } \\
\text { Superior } \\
\text { Desafio Universitário Empreendedor }\end{array}$ \\
\hline
\end{tabular}

Fonte: SEBRAE Minas, 2017c.

A educação básica incentiva os alunos no autoconhecimento, atuando de forma transformadora e incentivando a gestão da própria vida dos potenciais, aprendendo a conhecer, 
fazer, viver juntos e ser. Já a etapa voltada para o ensino médio, sendo três cursos, visa o crescimento integral do jovem, preparando-o para os desafios e identificação de oportunidades. $\mathrm{O}$ último módulo a ser desenvolvido é na educação superior, que tende a um sucesso profissional, focando no planejamento de vida e carreira, refletindo sobre as oportunidades de vida (SEBRAE Nacional, 2017b, on-line).

Para que haja essa dispersão do empreendedorismo e o bom funcionamento do programa do empreendedorismo, a parceria entre SEBRAE, escolas e educadores, é fundamental, isso acontece diretamente, além desses envolvidos temos os que envolvem indiretamente, sendo eles, a família e sociedade para a transformação do perfil dos estudantes. A ação da escola nessa participação possibilita a qualificação do professor para difundir aos alunos a interação tornando referência na formação dos seus alunos e esse potencial produz em suas famílias as ações praticadas em sala, melhorando até mesmo a renda familiar trazendo para a sociedade o desenvolvimento local.

\section{Procedimentos Metodológicos}

O mapeamento dessa pesquisa foi delimitado na Região do Noroeste Mineiro, a maior produtora de grãos do estado de Minas Gerais, que abrange a Microrregião de Unaí com os municípios de Bonfinópolis de Minas, Buritis, Cabeceira Grande, Dom Bosco e Natalândia, a Microrregião de Paracatu com os municípios de Biquinhas, Brasilândia de Minas, Guarda-Mor, João Pinheiro, Lagamar, Lagoa Grande, Morada Nova de Minas, Paineiras, Presidente Olegário, Santa Fé de Minas, São Gonçalo do Abaeté, Três Marias, Varjão de Minas e Vazante e a Microrregião de Arinos que atende os municípios de Chapada Gaúcha, Formoso, Pintópolis, Riachinho, São Romão, Uruana de Minas e Urucuia, ilustrados na Figura 1. Os pontos de atendimentos dessa região ficam situados nas cidades de Arinos, Paracatu e Unaí oferecendo orientações a gestão de empresas, palestras, cursos, seminários, consultorias e visitas empresariais. Além disso, conta com o programa da Educação Empreendedora que é disseminado em toda a região (SEBRAE MINAS, 2018a).

Figura 1: Mapa Regional Noroeste



Fonte: SEBRAE Minas, 2018a.

Essa pesquisa pode ser caracterizada de abordagem qualitativa, com finalidade explicativa e de instrumento documental. Documental por ter análise de dados secundários com natureza qualitativa afim de analisar dados teóricos e por proximidade direta da fonte, respeitando as particularidades e privacidade das informações com objetivo explicativo em que são evidenciados 
os pontos positivos dos resultados não deixando de lado as consequências encontradas nessa pesquisa.

A pesquisa primaria foi realizada pelo SEBRAE recentemente por meio do Radar da Educação Empreendedora para Instituições de Ensino, uma ferramenta com atributos que permitem apurar o grau de implementação de ações do Programa de Educação Empreendedora. O Radar da Educação Empreendedora para Instituições de Ensino foi aplicado em escolas que participaram do Programa no ano de 2017 e primeiro semestre de 2018 da regional noroeste, ilustradas na figura 1, com o objetivo se tornarem instituições norteadas pelos princípios da Educação Empreendedora, entendendo e escutando o depoimento dessas escolas.

Foram disponibilizadas três devolutivas de escolas das cidades de Arinos, Paracatu e Unaí com três tipos de graus de implementação sendo eles; alto, médio e baixo aleatoriamente com o intuito de se analisar os diferentes tipos de graus de implementação, comparando uma escola com a outra, e não se limitando somente nas escolas com maiores ou menores resultados. Ressalto que as escolas atendidas trabalham com o Ensino Fundamental.

A ferramenta utilizada foi o Radar da Educação Empreendedora para Instituições de Ensino proposta pelo SEBRAE Minas (2018b, on-line). Essa ferramenta é simples de ser preenchida e formada inicialmente por dados básicos da escola, sempre acompanhada por analista do SEBRAE para auxílio no preenchimento. A primeira parte a ser preenchida pela escola é a dimensão atores, composta por questões relacionadas a projetos, atividades, parceiros locais, participação de professores, equipes pedagógicas, alunos comunidade e direção na participação de projetos, atividades e parcerias dos projetos da educação empreendedora.

A segunda dimensão fala sobre políticas públicas e os principais desafios e problemas do município, leis municipais que promovam a educação empreendedora e participação da instituição de ensino em comitês ou grupos de trabalhos no desenvolvimento socioeconômico.

A terceira dimensão trata do tema de estrutura, relacionando o espaço que favorece a geração, criação, compartilhamento de ideias, desenvolvimento de projetos e também do conhecimento de estruturas de parceiros. A quarta dimensão é sobre recursos, como as fontes econômicas e financeiras que podem contribuir com os projetos e desenvolvimentos de ações. A quinta e última dimensão é cultura que explana a importância do conhecimento da instituição sobre a educação empreendedora, aplicando os conhecimentos a alunos, professores de forma continuada, a percepção de resultados significativos, mudanças em práticas pedagógicas, eventos e envolvimento da comunidade (SEBRAE Minas, 2018b, on-line).

Essas 5 dimensões formam o Ecossistema da Educação Empreendedora que, unidas geram engajamento e resultados de boas práticas para o processo de aprendizagem, além da geração, desenvolvimento, aplicação e compartilhamento de ideias e projetos.

Assim, ao término da aplicação do Radar pressupõe uma devolutiva digital ou manual de forma simples e compacta entregue nas instituições a fim de avaliar o grau de implementação e disseminação dessa cultura além da própria instituição se auto avaliar, considerando que tenha um alto grau, médio grau ou baixo grau de implementação para projetos de Educação Empreendedora. Para análise dessas devolutivas, foi feita uma interpretação confrontando os níveis, extraindo as semelhanças e garimpando as poucas diferenças nos resultados de cada dimensão comparados entre si.

O resultado do Radar da Educação Empreendedora para Instituições de Ensino e expresso por meio da análise das cinco dimensões avaliadas, e cada dimensão pode ser classificada em relação ao grau de implementação com grau alto, médio e baixo. Este resultado também constitui de uma atribuição de pontuação para cada dimensão, cujo resultado e a somatória de cada dimensão, cuja pontuação máxima é 48 pontos, somadas as cinco dimensões, e em percentual, que 
compreende ao somatório de cada dimensão, cujo resultado ilustra o grau de implementação do Ecossistema da Educação Empreendedora (SEBRAE Minas, 2018b, on-line).

Os procedimentos adotados na coleta de dados foi uma pesquisa documental, onde segundo Gil (2007), este procedimento se utiliza de fontes documentais, isto é, fontes de dados secundários. Os dados secundários foram coletados junto ao SEBRAE Minas, através da análise das devolutivas geradas através do Radar da Educação Empreendedora para Instituições de Ensino, aplicado às instituições de ensino participantes da Regional Noroeste do SEBRAE Minas.

A análise de dados foi realizada a luz da análise de conteúdo proposta por Bardin (2006, p.38), cuja definição consiste em "um conjunto de técnicas de análise das comunicações, que utiliza procedimentos sistemáticos e objetivos de descrição do conteúdo das mensagens. Onde na pesquisa consistiu em analisar o conteúdo das devolutivas e inferir uma discussão a respeito das contribuições do SEBRAE para tal prática. Nesse contexto, essa pesquisa destaca-se pela importância do papel do SEBRAE com o Programa Educação Empreendedora que agrega para os potenciais empreendedores as condições que desenvolvam competências e habilidades que estimulem a identificação de oportunidades e interesses, estando lado a lado no potencial do educador de transformar ideias e visões em projetos passiveis de serem executados.

\section{Análise e Discussão dos Resultados}

O SEBRAE como uma referência na disseminação do empreendedorismo no país e com o Programa da Educação Empreendedora, desenvolveu o Radar da Educação Empreendedora a fim de verificar as ações realizadas para avaliar o feedback e acompanhar se há continuação do aprendizado. Assim para entender e acompanhar de perto essa ferramenta recém-criada e utilizada pelo SEBRAE utiliza-se a devolutiva que é a entrega final da ferramenta para a instituição como forma de avaliar as possíveis mudanças e o SEBRAE acompanhar os resultados das ações.

Nesta pesquisa foram examinadas três devolutivas com resultados nos três níveis diferentes, utilizando o mesmo nível de escolaridade para analisar os dados obtidos, ressaltando que uma escola é atendida pelo ponto de atendimento de Arinos, outra pelo ponto de atendimento de Unaí e outra pelo ponto de atendimento de Paracatu formando a Regional Noroeste de Minas, é cada escola com um nível de resultado diferente, sendo um alto, médio e baixo aleatoriamente.

O cuidado na escolha dos resultados se deu ao ponto de analisar todos os três graus e suas condições. Para manter o nome das instituições no anonimato, as mesmas foram nomeadas como escolas A, B e C e consequentemente alto, médio e baixo. A apresentação dos resultados das devolutivas será sequencialmente, $\mathrm{A}, \mathrm{B}$ e C, em que são exibidos os dados individuais das escolas, e posteriormente, um apanhado das análises encontradas. A primeira escola apresentada será a A, conforme resultados ilustrados no Quadro 2.

Quadro 2: Dados da escola A

\begin{tabular}{|c|c|c|c|c|c|c|c|}
\hline Geral & Atores & Cultura & Estrutura & Recursos & Políticas públicas & Pontos & $\%$ \\
\hline Alto & Médio & Alto & Alto & Alto & Alto & 44 & 91,67 \\
\hline
\end{tabular}

Fonte: Dados da pesquisa, 2018.

Atores - A instituição de ensino conhece grande parte dos atores necessários para o desenvolvimento da Cultura Empreendedora, reconhece a importância de interagir com eles, mas realiza poucas ações de articulação e engajamento desses atores para otimizar o processo de desenvolvimento e disseminação da Cultura Empreendedora. 
Cultura - A instituição de ensino demonstra compreender a importância de oportunizar experiências significativas para os atores do Ecossistema de Educação Empreendedora. Percebe o quanto estas experiências geram engajamento e resultados relevantes para o processo de aprendizagem e atua com foco na promoção e na manutenção de um ambiente favorável ao desenvolvimento e disseminação da Cultura Empreendedora.

Estrutura - A instituição demonstra conhecer e utilizar espaços internos ou de parceiros para geração, colaboração, compartilhamento e prototipação de ideias e projetos. Reconhece a importância desses espaços e quando não os possui, e improvisa espaços ou a busca fora da instituição de ensino para possibilitar o processo de desenvolvimento de novos projetos. Desta forma, também demonstra cultivar relacionamentos e parcerias com instituições que possuem e disponibilizam estes espaços.

Recursos - A instituição demonstra conhecer as diversas fontes de recursos financeiros e econômicos que podem contribuir com a viabilização dos projetos e iniciativas para implementação da Educação Empreendedora. Utiliza das experiências exitosas para participar de concursos, editais e outras possibilidades que possam gerar premiações, parcerias e reconhecimento. Além disso, percebe a importância da interação com instituições de apoio e fomento para fortalecer, solidificar e disseminar a Cultura Empreendedora.

Políticas públicas - A instituição reconhece relevância de se ter no Projeto Político Pedagógico, diretrizes para o tema de Empreendedorismo e Educação Empreendedora, reconhece o seu papel como agente de desenvolvimento da sociedade, por isso, participa de comitês ou grupos de trabalhos que tenham como objetivo tratar de assuntos relacionados ao desenvolvimento socioeconômico do território ou do município. Além disso, utiliza das diversas iniciativas de políticas públicas do município e da região para articular a institucionalização, fomento, e desenvolvimento da Cultura Empreendedora.

Em geral de acordo com as respostas, a instituição de ensino A apresenta um grau de implementação ALTO para o desenvolvimento de uma ambiência favorável a implementação da Educação Empreendedora. Esse contexto sinaliza que a instituição possui uma visão sistêmica e promove ações que irão gerar experiências significativas e relevantes em cada uma das dimensões do Ecossistema da Educação Empreendedora, de forma equilibrada. Além disso, a instituição já consegue perceber que, na medida em que o ecossistema evolui e fortalece, é necessário criar estratégias para manter essas ações integradas para continuar usufruindo de um ambiente propício à formação de jovens empreendedores que, imbuídos na cultura empreendedora, atuarão como agentes de transformação de sua realidade em busca de uma sociedade com mais oportunidades e prosperidade.

Os resultados da escola B estão ilustrados no Quadro 3.

Quadro 3: Dados da escola B

\begin{tabular}{|c|c|c|c|c|c|c|c|}
\hline Geral & Atores & Cultura & Estrutura & Recursos & Políticas públicas & Pontos & $\%$ \\
\hline Médio & Alto & Alto & Médio & Baixo & Baixo & 31 & 64,58 \\
\hline
\end{tabular}

Fonte: Dados da pesquisa, 2018.

Atores - A instituição de ensino conhece todos, ou grande parte, dos atores necessários para o desenvolvimento da Cultura Empreendedora, reconhece a importância de interagir com eles e atua com foco na realização de ações de articulação e engajamento desses atores para otimizar o processo de desenvolvimento e disseminação da Cultura Empreendedora. 
Cultura - A instituição demonstra compreender a importância oportunizar experiências significativas para os atores do Ecossistema de Educação Empreendedora. Percebe o quanto estas experiências geram engajamento e resultados relevantes para o processo de aprendizagem e atua com foco na promoção e na manutenção de um ambiente favorável ao desenvolvimento e disseminação da Cultura Empreendedora.

Estrutura - A instituição de ensino demonstra conhecer a relevância de utilizar espaços internos ou de parceiros para a geração, colaboração, compartilhamento e prototipação de ideias e projetos, mas ainda não possui esta prática pedagógica. Reconhece a importância desses espaços para possibilitar o processo de desenvolvimento de novos projetos, mas ainda possui poucas iniciativas com este propósito, o que demonstra cultivar poucos relacionamentos e parcerias com instituições que possuem e disponibilizam estes espaços.

Recursos - A instituição demonstra desconhecer e não usufrui das diversas fontes de recursos financeiros e econômicos que podem contribuir com a viabilização dos projetos e iniciativas para a implementação da Educação Empreendedora, por isso, não participa de iniciativas para se beneficiar destas oportunidades. Além disso, ainda não percebe a importância de interagir com instituições de apoio e fomento para fortalecer, solidificar e disseminar a Cultura Empreendedora.

Políticas públicas - A instituição de ensino ainda não percebe a relevância de se ter no Projeto Político Pedagógico, diretrizes com o tema de Empreendedorismo e Educação Empreendedora, também não se apropriou de seu papel como agente de desenvolvimento da sociedade, por isso não participa de comitês ou grupos de trabalhos que tenham como objetivo tratar de assuntos relacionados ao desenvolvimento socioeconômico do território ou do município. Além disso, desconhece ou utiliza muito pouco das diversas iniciativas de políticas públicas do município e da região para articular a institucionalização, fomento, e desenvolvimento da Cultura Empreendedora.

De acordo com as respostas, a instituição de ensino B apresenta um grau de implementação MÉDIO para o desenvolvimento de uma ambiência favorável à implementação da Educação Empreendedora. As ações ainda estão concentradas em algumas dimensões. Esse contexto sinaliza que a instituição precisa melhorar sua visão sistêmica para promover ações que irão gerar experiências significativas e relevantes em cada uma das dimensões do Ecossistema de Educação Empreendedora, de forma equilibrada. Além disso, a instituição percebe a importância e a relevância, mas precisa otimizar os esforços para criar estratégias e ações integradas para a sustentabilidade do ecossistema e, assim, continuar usufruindo de um ambiente propício à formação de jovens empreendedores que, imbuídos na cultura empreendedora, atuarão como agentes de transformação de sua realidade em busca de uma sociedade com mais oportunidades e prosperidade. Ainda são necessários ajustes, mas a instituição está no caminho certo.

Os resultados da escola C estão ilustrados no Quadro 4.

Quadro 4: Dados da escola C

\begin{tabular}{|c|c|c|c|c|c|c|c|}
\hline Geral & Atores & Cultura & Estrutura & Recursos & Políticas públicas & Pontos & $\%$ \\
\hline Baixo & Médio & Baixo & Alto & Baixo & Baixo & 26 & 54,17 \\
\hline
\end{tabular}

Fonte: Dados da pesquisa, 2018.

Atores - A instituição de ensino conhece grande parte dos atores necessários para o desenvolvimento da Cultura Empreendedora, reconhece a importância de interagir com eles, mas realiza poucas ações de articulação e engajamento desses atores para otimizar o processo de desenvolvimento e disseminação da Cultura Empreendedora. 
Cultura - A instituição demonstra pouca compreensão da importância de oportunizar experiências significativas para os atores do Ecossistema de Educação Empreendedora. Ainda não percebe o quanto estas experiências geram engajamento e resultados relevantes para o processo de aprendizagem, por isso, realiza poucas ações que contribuam efetivamente na manutenção de um ambiente favorável ao desenvolvimento e disseminação.

Estrutura - A instituição de ensino demonstra conhecer e utilizar espaços internos ou de parceiros para a geração, colaboração, compartilhamento e prototipação de ideias e projetos. Reconhece a importância desses espaços e quando não os possui, improvisa espaços ou a busca fora da instituição de ensino para possibilitar o processo de desenvolvimento de novos projetos. Desta forma, também demonstra cultivar relacionamentos e parcerias com instituições que possuem e disponibilizam estes espaços.

Recursos - A instituição demonstra desconhecer e não usufrui das diversas fontes de recursos financeiros e econômicos que podem contribuir com a viabilização dos projetos e iniciativas para a implementação da Educação Empreendedora, por isso, não participa de iniciativas para se beneficiar destas oportunidades. Além disso, ainda não percebe a importância de interagir com instituições de apoio e fomento para fortalecer, solidificar e disseminar a Cultura Empreendedora.

Políticas Públicas - A instituição de ensino ainda não percebe a relevância de se ter no Projeto Político Pedagógico, diretrizes com o tema de Empreendedorismo e Educação Empreendedora, também não se apropriou de seu papel como agente de desenvolvimento da sociedade, por isso não participa de comitês ou grupos de trabalhos que tenham como objetivo tratar de assuntos relacionados ao desenvolvimento socioeconômico do território ou do município. Além disso, desconhece ou utiliza muito pouco das diversas iniciativas de políticas públicas do município e da região para articular a institucionalização, fomento, e desenvolvimento da Cultura Empreendedora.

De acordo com as respostas, a instituição de ensino $\mathrm{C}$ apresenta um grau de implementação BAIXO para o desenvolvimento de uma ambiência favorável à implementação da Educação Empreendedora. As ações ainda estão concentradas em algumas dimensões. Esse contexto sinaliza que a instituição precisa desenvolver sua visão sistêmica para promover ações que irão gerar experiências significativas e relevantes em cada uma das dimensões do Ecossistema de Educação Empreendedora, de forma equilibrada. Além disso, a instituição precisa reconhecer que, na medida em que o ecossistema amadurece e fortalece, ela precisará criar estratégias para manter essas ações integradas para continuar usufruindo de um ambiente propício à formação de jovens empreendedores que, imbuídos na cultura empreendedora, atuarão como agentes de transformação de sua realidade em busca de uma sociedade com mais oportunidades e prosperidade. Ainda são necessários ajustes significativos, mas a instituição está no caminho certo.

Embora a devolutiva do Radar já seja auto explicativa, analisa-se e intensifica-se no que as instituições com graus menos elevados podem se atentar para melhorar o empreendedorismo escolar, compreendendo a realidade das instituições, ou seja, a realidade da educação do nosso país e por mais que o SEBRAE atue de forma ampla na disseminação do empreendedorismo precisamos captar as reais necessidades e a importância de parcerias na realização e promoção do empreendedorismo dentro das escolas.

Com as devolutivas entregues nas escolas, como uma forma de apresentar um resultado do que já foi implementado naquela escola e obter um feedback da própria instituição como forma de entender a sua necessidade na continuação do programa, pode-se perceber que as três devolutivas são bastante similares nos conteúdos apresentados mesmo que os resultados entre alto, médio e baixo sejam distintos. Portanto aqui, faz uma análise geral das três devolutivas levando em consideração o papel de cada dimensão e sua importância. 
Entende-se que a instituição que apresenta um resultado alto em uma dimensão positivamente está realizando ações e projetos de acordo com estudado e, em conformidade com a instituição, cria suas próprias estratégias para manter os resultados positivos. Assim, a análise está com foco nas instituições com resultados menos elevados, apresentando indicadores de possíveis melhorias. Sabe-se que as 5 dimensões juntas formam o Ecossistema, porém compreende-se que parte delas tem seus papeis independentes e conseguem também realizar trabalhos na disseminação do empreendedorismo.

Analisam-se as dimensões individualmente para que se entenda que o SEBRAE tem a base na capacitação do educador, fornece material para que isso aconteça, mas, sozinho não pode realizar seu trabalho, assim através de parcerias esse trabalho se torna mais simples, com mais empenho e engajamento de todos. As dimensões sempre são analisadas respectivamente instituições A, B e C.

$\mathrm{Na}$ dimensão de Atores que as escolas A, B e C apresentam resultados respectivamente médio, alto e médio. Entende-se que o resultado é considerado positivo porque não apresenta nessa dimensão nenhum com resultado baixo. Analisam-se atores e entende-se que esses atuam e representam a instituição de ensino e que não dependem de outras parcerias para realização de ações, pois estão concentradas na instituição, educadores e orientadores, ressalta-se uma necessidade de implementação nos planos de aula, programações da escola, feiras e metodologias para demonstrar não só para outros alunos, como escolas e comunidade a linha do aprendizado do educador através da educação empreendedora, criando soluções de atuações protagonistas desses alunos e retratando a importância do papel deles na comunidade local. Assim como, a criação de planilhas de controles financeiros, vendas e projetos empreendedores relacionado à finanças para facilitar o entendimento desses alunos e continuação do aprendizado.

No entendimento de Bruner (1991), as crianças apresentam uma curiosidade natural, e o aproveitamento deste potencial devem ser observados pelos educadores, pois ambos estão compreendidos no ambiente atores, e podem contribuir para a construção de um ambiente propicio para efetivação da educação empreendedora. O ator também tem uma troca de informações, aprendizagens e experiências a partir da interação de educador e aluno, facilitando e agregando uma participação maior de ambos. É fundamental o papel da direção como apoiadora desses propósitos para que os educadores tenham um suporte e incentivo, visto que educadores são os principais capacitados e transmissores do conhecimento e mais do que isso eles precisam estar empenhados. Essa dimensão é muito importante e tem um poder de ação grande mesmo que sem as outras dimensões, porém quando todos se engajam esse trabalho se torna ainda mais simples de ser realizado.

A próxima dimensão analisada é a Cultura. As escolas A, B e C apresentam os seguintes resultados: alto, alto e baixo. Entende-se por cultura o cultivo das crenças, tradições e conhecimentos preservados de gerações em gerações em regiões, considerado de suma importância em nosso país e como uma preservação do passado e história do Brasil. Segundo Schmidt \& Dreher (2008) a cultura empreendedora de uma nação pode ocorrer de diversas maneiras, como, por exemplo, por meio do perfil empreendedor, do empreendedorismo coletivo, da gestão empreendedora, entre outras formas. A existência e a combinação de algumas dessas e outras manifestações é o que, de fato, constrói uma cultura empreendedora (Dreher, 2004).

Desse modo, as instituições também devem trabalhar de forma a entender e propiciar um ambiente empreendedor de acordo com os hábitos locais, buscando iniciativas para trazer indicadores do empreendedorismo da região, assim também é muito comum o empreendedorismo familiar, aumentando nessas crianças e adolescentes o interesse por práticas desenvolvidas externamente. As instituições podem buscar indicadores para trabalhar o desenvolvimento local, atribuindo responsabilidades limitadas aos participantes.

Para que estas instituições propiciem um ambiente propício às ações empreendedoras por parte dos alunos, Mota \& Pereira (2007) cita alguns fatores prementes, entre eles o talento do professor, o tipo intelectual do aluno, as oportunidades oferecidas pelo ambiente imediato da escola, 
e perspectivas futuras de vida do aluno. O ambiente que a escola recria, produz incentivos nos potenciais para a geração de boas práticas empreendedoras realizadas nas escolas, assim eles podem também contribuir com experiências e opiniões causando um impacto significativo, quando o comportamento empreendedor é trabalhado a cultura é trabalhada, portanto de acordo com Silva, Gomes \& Correia (2009) vários fatores influenciam o nível de atividade empreendedora de um país, dentre eles as características culturais exercem sua influência direta. Vários estudos apontam que os fatores culturais de uma nação, juntamente com o seu ambiente, afetam o comportamento dos empreendedores de maneira significativa (Tan, 2002). Mota \& Pereira (2007) ressalta que o papel da escola atualmente uma simples máquina de alfabetização, cuja sua função não se restringe mais, à modesta tarefa de ensinar, sua tarefa é mais ampla e profunda, ou seja, deve levar o nosso aluno a ser mais crítico, mais compromissado e mais otimista em relação à aprendizagem.

A terceira dimensão Recursos apresentou resultados mais negativos entre as instituições sendo alto, baixo e baixo. Essa dimensão como representada nos resultados, é mais fragilizada nas instituições não somente como recurso líquido, mas também físico. Sabe-se que o desafio que a instituição tem de transformar o pouco em muito é um problema real, ou seja, é preciso fazer muito mais do que é oferecido à instituição. É preciso identificar e mapear as necessidades de cada instituição de forma a entender a situação e da melhor forma buscar um meio de atrair e não deixar decair pelas necessidades, de tal modo buscar experiências em outras instituições e também parcerias para facilitar e proporcionar alavancar as atuações. Esses recursos de parceiros como um laboratório para que possam ter acesso a mais informações e internet e buscar ideias, deixam o potencial com maior atratividade pelo seu próprio desenvolvimento, reagindo aos apoios básicos.

Entretanto destaca Nicola \& Paniz (2016) que com os resultados positivos obtidos com os recursos utilizados, atuam como fatores motivadores dos alunos, levando-os a se interessar por novas situações de aprendizagem, e na interação como os recursos, construir conhecimentos mais complexos, como o empreendedorismo. Aqui também é importante ressaltar a parcerias com as Prefeituras locais, Secretarias de Educação, Superintendências de Ensino e demais parceiros da educação como auxiliadores na busca de recursos.

A quarta dimensão Estrutura, nas instituições A, B e C tem resultados alto, médio e alto. Essa se refere aos espaços internos e externos para realização dos projetos desenvolvidos, aqui apresentamos duas escolas com bons resultados. Assim entendemos que os espaços físicos delas atendem às necessidades atuais, entretanto temos uma instituição que tem requisito mediano em relação a essa dimensão. Para ela é indicado que tenha à disposição espaços externos, sejam eles praças, quadras e até espaços de outras instituições promovendo novas experiências e atividades pedagógicas que desenvolvam comportamentos empreendedores. A infraestrutura escolar pode exercer influência significativa sobre a qualidade da educação, bem como no ambiente empreendedor. Para Satyro \& Soares (2007) um ambiente que possibilite um melhor desenvolvimento dos alunos deve ser compreendido por prédios e instalações adequadas, existência de biblioteca escolar, espaços esportivos e laboratórios, acesso a livros didáticos, materiais de leitura e pedagógicos. Deste modo, entendemos que estrutura não se trata exatamente da dimensão da instituição e sim de todos os insumos que a compõem.

É possível perceber que a estrutura escolar é determinante para um bom funcionamento de uma escola, pois sem uma boa estrutura, não se pode esperar um bom funcionamento, e mesmo que venha a ter o bom funcionamento a organização da estrutura escolar implicará na qualidade da educação, bem como na construção de um ambiente empreendedor.

E por último das 5 dimensões temos a Políticas Públicas, como resultados das instituições alto, baixo e baixo respectivamente. Aqui abordamos das políticas públicas educacionais, como se refere Oliveira (2010) que a educação é um conceito muito amplo para se tratar das políticas educacionais. Isso quer dizer que políticas educacionais é um foco mais específico do tratamento da 
educação, que em geral se aplica às questões escolares. Deste modo a instituição pode trabalhar de forma mais assertiva o PPE - Projeto Político Pedagógico.

Nesse documento interno da instituição, pode ser inserido por meio de reuniões e alternativas da participação de gestores escolares a inserção de conteúdos programáticos, disciplinas e ferramentas para amparo desses planos. Assim, a inciativa também pode beneficiar a comunidade com feiras, buscando apoio de parceiros nas informações, vendas de produtos, divulgação das tarefas dos alunos e uma interessante iniciativa é buscar empreendedores já segmentados para proferir do assunto.

Completa-se a apreciação das cinco dimensões e observa-se a participação de cada uma e a unificação de todas formando o Ecossistema de Educação Empreendedora, percebe-se que ele apresenta efeitos expressivos, embora o ideal é o engajamento de todas as dimensões. Nota-se que as dimensões que não necessitam de soluções externas como parceiros, recursos financeiros e etc., esses se desenvolvem mais como, a dimensão atores e cultura que dependem de papeis atuantes locais. Assim também podemos interpretar que as dimensões de recursos e políticas públicas que têm um envolvimento mais abrangente possuem resultados mais baixos. Apesar de a dimensão atores apresentar duas escolas com resultados medianos, podemos destacar a importância dos educadores, com papéis e atitudes iniciantes realizando seu trabalho isoladamente a partir de uma iniciativa como influenciador e estimulador.

O papel do professor é ir desembaraçando as ideias e encaixando em seus protagonistas sendo de importante atuação, conforme Liberato $(2018$, p. 1) “... o professor, empreendedor por natureza, é agente determinante na construção dos saberes e das novas competências, cabendo-lhe a missão de preparar esses jovens para uma nova Era..." o seu trabalho envolve direcionamento e perspectivas futuras.

Muitos são os obstáculos para que essa disseminação aconteça e uma delas é a participação dos professores, pois o interesse deles é fundamental para que a escola cresça nesse âmbito, também é preciso recursos financeiros para incentivos dos alunos e também desses professores. A escola deve trabalhar sempre a melhoria contínua criando estratégias para se manter em um nível bom e estar em constante desenvolvimento. Como mencionado anteriormente, e já fazendo parte da nossa análise, esse trabalho realizado nas escolas com professores e posteriormente aplicado aos alunos necessita de tempo para que resultados sejam apurados e visíveis.

A partir dessa análise entende-se que o grau baixo da instituição e também representando outras instituições nesse mesmo resultado, não quer dizer necessariamente que a instituição é ruim para disseminação e implementação do empreendedorismo, mas sim podemos entender que ela não tem favorecimento em algumas dimensões, como por exemplo, a dimensão recursos que necessita de parceiros e ajuda para se manter, portanto a escola que apresenta um nível baixo do programa deve buscar ajuda, seja ela em relacionamentos duradouros e eficazes, como também recursos buscando iniciativas para criar possibilidades desenvolvimento educacional.

Para Andrade \& Raitz (2012, p. 3), além dessas razões, também podemos expandir para inúmeras outras, uma delas é a “... a não valorização dos profissionais, a participação não efetiva dos pais e professores na escola, a falta de vontade por parte dos alunos em aprender..." ,ou seja, várias são as dificuldades encontradas e os impasses para não só esses projetos da Educação Empreendedora acontecer como muitos outros dentro da instituição, o que vale a pena ressaltar é o engajamento de todos os envolvidos e a vontade para que cada ação aconteça e valorize a aprendizagem, conhecimento, instituição e comunidade.

Conforme Dias, Oliveira, Souza, Silva \& Suassuna (2015) outros fatores também contribuem para a construção do ecossistema empreendedor, como os vínculos afetivos e emocionais entre a família, pois a presença e participação da família na vida do aluno bem como do ambiente escolar contribuem para efetivação de práticas empreendedoras. A família se torna um 
parceiro externo nesse ciclo, apoiadora, participante e presente nos resultados, assim essa aproximação gera bons relacionamentos e resultados entre aluno/família e escola.

Ressalta-se que esse estudo de análise nas instituições por dimensão é teórico, esclarecendo abertamente que na prática inúmeros desafios são encontrados nessas escolas e que cada escola possui perfis diferentes e problemas reais distintos. Assim as dificuldades vão desde uma escola com recursos desfavorecidos a uma que possui uma má gestão não sabendo onde aplicar os recursos, como também a escola que, com poucos recursos, possui atores que ocupam papéis importantíssimos dentro de uma escola e torna com o pouco o melhor a ser feito.

O que pode ser realizado para favorecer as instituições com níveis baixos, é um levantamento de atuações dentro da devolutiva do SEBRAE, criando um mapeamento das dificuldades e formas de melhorá-las, também buscando em instituições com níveis superiores uma forma de incentivo para si, entendendo a forma de ação das demais para que possam também utilizar das melhores práticas para aperfeiçoar seu processo na disseminação da educação empreendedora.

\section{Considerações Finais}

A qualidade de vida das pessoas de um país pode estar correlacionada ao ambiente empreendedor existente nele. Já a geração de riquezas de um país está diretamente relacionada ao comportamento empreendedor de sua população. E iniciar o ambiente empreendedor, pode correlacionar questões sociais e econômicas ligadas diretamente ao futuro das pessoas. Quando trabalha educação já inicia a geração de valor, quando unem educação e empreendedorismo estamos gerando não só valor como também produzindo o futuro do país.

Assim o Programa de Educação Empreendedora trabalhado na região traz metodologias atualizadas, materiais de qualidade e conhecimento para que possam ser semeados pelos principais atores. Quando se refere a atores, citam-se os professores, principais agentes de transformação, que têm a capacidade de um único professor expandir o conhecimento adquirido para muitos potenciais formadores do país, esses que serão empreendedores, também é importante destacar aqui a participação da escola como apoiadora, sustentadora e incentivadora desse programa. Outros atores que merecem destaque na construção do ambiente empreendedor é a participação da comunidade, do poder público e das empresas locais, como agentes motores do processo de construção de um ambiente empreendedor dentro das escolas.

Para objetar a questão de pesquisa que direciona esse artigo, pôde-se analisar a importância da Educação Empreendedora trabalhada na Regional Noroeste do SEBRAE Minas, que apresenta resultados positivos e que mantém o elo com os interessados na disseminação do empreendedorismo, assim também mesmo com a base do SEBRAE existem escolas que possuem suas dificuldades sejam elas de recursos, atores, estrutura, cultura ou políticas públicas, como analisados anteriormente. Entretanto apesar das dificuldades enfrentadas por essas escolas e professores nessa dispersão, pode-se considerar que nossa região é uma região de grande potencial e que futuramente surgiram casos com grandes sucessos. $\mathrm{O}$ crescimento desse tipo de educação nas escolas é importante quando aprimorado no âmbito do desenvolvimento econômico, social e sustentável, na concepção de novos empregos para a humanidade que já sofre com o desemprego em nível nacional, tornando não só empreendedores preocupados com o futuro do país como o surgimento de novos empreendedores e empresas afins de utilizarem dos recursos atuais de forma consciente para gerações futuras buscando a redução dos efeitos negativos, trazendo melhores condições de vida e amenizando desigualdades.

Portanto a continuidade desse processo, com o fomento do SEBRAE, participação das escolas, iniciativa de professores e o apoio do município na propagação, execução e mensuração desses resultados, fazem com que os envolvidos obtenham resultados expressivos, impulsionado a 
concretização de novas ideias, personagens e escolas na mudança da realidade e trazendo um ambiente local mais desenvolvido.

Chama-se à atenção para as escolas que apresentam um alto nível da implementação do programa mantendo sempre o desenvolvimento como forma de perpetuar, para as escolas que apresentam níveis médio e baixo. É necessária uma revisão da própria instituição para análise das carências, facilitando assim a busca na melhoria e sendo assertivo nas necessidades.

Esse estudo colaborou para a visão e expansão da importância da educação empreendedora na regional juntamente com o Ecossistema, o apoio do SEBRAE e participação dos demais envolvidos atuando como uma oportunidade que além de repassar conhecimentos é gratuito.

As estreitas limitações desse estudo estão no não acompanhamento do procedimento de uma forma intrínseca, uma presença do início desde à capacitação até implementação do conteúdo, de forma a entender as necessidades das escolas, dificuldades por menores que sejam e acompanhar de perto o que realmente é eficaz. Portanto deixa espaços para uma pesquisa de campo onde possa haver um acompanhamento e supervisão dessas escolas identificando possíveis melhorias para que o papel do SEBRAE venha trazer ainda mais resultados relevantes. Outra indicação de futuras pesquisas se concentra nas características in loco de cada instituição como fatores influenciadores da implementação de empreendedorismo, bem como a replicação dessas características em outras realidades.

\section{Referências}

Andrade, C., \& Raitz, T. R. (2012). As possíveis razões do sucesso escolar em duas escolas públicas. In Anais do Seminário de Pesquisa em Educação da Região Sul, IX. Caxias do Sul, RS, Brasil.

Ângelo, E. B. (2003) Empreendedor Coorporativo: a nova postura de quem faz a diferença. Rio de Janeiro: Elsevier.

Baggio, A. F., \& Baggio, D. K. (2014) Empreendedorismo: Conceitos e Definições. Revista de Empreendedorismo, Inovação e tecnologia, 2014.

Bardin, L. (2006). Análise de conteúdo (L. de A. Rego \& A. Pinheiro, Trads.). Lisboa: Edições 70. (Obra original publicada em 1977)

Bruner, J. (1991) O Processo da educação Geral. 2a ed. São Paulo: Nacional.

Chaer, T. (2018) Novo olhar para o futuro da educação - entrevista com Thiago Chaer. 2018. Recuperado em 12 de abril 2018, de http://cer.SEBRAE.com.br/novo-olhar-para-o-futuro-daeducacao-entrevista-com-thiago-chaer/.

Cury, A. (2005) Nunca desista de seus sonhos. Rio de Janeiro: Sextante.

Dias, S. G., Oliveira, F. P de., Souza, J. N. P. de., Silva, L. B. da., \& Suassuna, M. A. F. M. (2015) A importância da participação dos pais na educação dos filhos no contexto escolar. In Anais Congresso Nacional de Educação. II. Campina Grande, PB, Brasil.

Dornelas, J. C. A. (2008) Empreendedorismo: transformando ideias em negócios. 1971. 3. ed. Rio de Janeiro: Elsevier.

Dolabela, F. (1999a) Oficina do Empreendedor. São Paulo: Cultura.

Dreher, M. T. (2004) Empreendedorismo e responsabilidade ambiental: uma abordagem de empreendimentos turísticos. Tese de Doutorado, Universidade Federal de Santa Catarina (UFSC). Programa de Pós-Graduação em Engenharia de Produção, Florianópolis, SC, Brasil.

Gil, A. C. (2007) Métodos e técnicas de pesquisa social. 5. ed. São Paulo: Atlas. 
Liberato, A. C. T. (2018). Empreendedorismo na escola pública: despertando competências, promovendo a esperança! Recuperado em 26 de outubro de 2018 de file:///C:/Users/linde/Downloads/empreendedorismo_escola_publica_teixeira.pdf.

Machado, J. P., Felix, J. C., Greco, S. M. S. S, Bastos Junior, P. A., Silvestre, R. G. M., Moraes, A. A., Côrtes, A. M., \& Friedlaender Junior, R. H. (2010) Empreendedorismo no Brasil: 2009. Curitiba: IBQP.

Melo, N. M. (2008) SEBRAE e empreendedorismo: origem e desenvolvimento. Dissertação de Mestrado, Universidade Federal de São Carlos, Programa de Pós-Graduação em Ciências Sociais, São Carlos, SP, Brasil.

Mota, M. S. G., \& Pereira, F. E. de L. (2007) Desenvolvimento e aprendizagem: processo de construção do desenvolvimento mental do indivíduo. Ed. Ministério de Educação, Brasília, 2007. Recuperado em 02 nov. 2018 de http://portal.mec.gov.br/setec/ arquivos/pdf3/tcc_desenvolvimento.pdf.

Nicola, J. A., \& Paniz, C. M. (2016) A importância da utilização de diferentes recursos didáticos no ensino de biologia. Infor, Inov. Form., Rev. NEaD-Unesp, São Paulo, v. 2, n. 1, p.355-381.

Oliveira, de A. F. (2010) Políticas públicas educacionais: conceito e contextualização numa perspectiva didática. In: OLIVEIRA, A. F. de. Fronteiras da educação: tecnologias e políticas. Goiânia-Goiás: PUC Goiás.

Roese, A., Binotto, E., \& Büllau, H. (2005) Empreendedorismo e a cultura empreendedora: um estudo de caso no Rio Grande do Sul. In Anais Seminário de Gestão de Negócios. II Blumenau, FAE, 2005.

Satyro, N., \& Soares, S. (2007) A infraestrutura das escolas brasileiras de ensino fundamental: um estudo com base nos censos escolares de 1997 a 2005. Brasília: IPEA.

Schmidt, C. M., \& Dreher, M. T. (2008). Cultura Empreendedora: Empreendedorismo Coletivo e Perfil Empreendedor. Revista de Gestão USP, São Paulo, v. 15, n. 1, p. 1-14, janeiro/março.

SEBRAE Minas. (2012). Empreendedores do futuro. Passo a Passo: na medida certa. VIII, 139, 382 , abril/maio.

SEBRAE Minas. (2017a). Metodologia. Recuperado em 22 mar. 2018 de http://www.SEBRAE.com.br/sites/PortalSEBRAE/ufs/mg/SEBRAEaz/programa-educacaoempreendedora-mg,b0cc1d6351ce3510VgnVCM1000004c00210aRCRD.

SEBRAE Minas. (2017b). Horizontes infinitos. Passo a Passo: empreendedorismo que faz escola. XXII, 166, 3-82, novembro 2016/janeiro.

SEBRAE Minas. (2017c) Soluções do Programa. Recuperado em 28 mai. 2018 de http://www.SEBRAE.com.br/sites/PortalSEBRAE/ufs/mg/SEBRAEaz/programa-educacaoempreendedora-

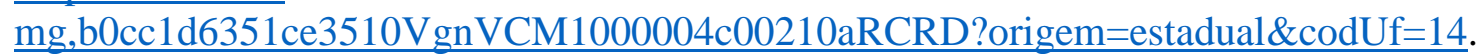

SEBRAE Minas. (2018a). Regional e Microrregião. Belo Horizonte.

SEBRAE Minas. (2018b). Radar de Educação Empreendedora para Instituições de Ensino. Belo Horizonte.

SEBRAE Nacional. (2017a). Educação Empreendedora para todos os níveis de ensino. Brasília. $\begin{array}{lllll}\text { Recuperado } & \text { em } & 22 & \text { abr. } & 2018\end{array}$ http://www.SEBRAE.com.br/sites/PortalSEBRAE/Programas/programa-nacional-da-educacaoempreendedora-pnee,2c7cd24a8321c510VgnVCM1000004c00210aRCRD. 
SEBRAE Nacional. (2017b). Educação Empreendedora na Educação Profissional. Brasília.

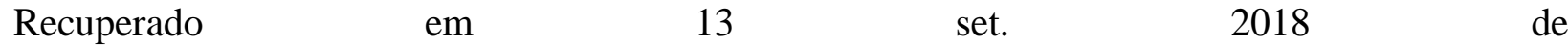
http://www.SEBRAE.com.br/sites/PortalSEBRAE/SEBRAEaz/educacao-empreendedora-noensino-tecnico,394ca15d81d36410VgnVCM2000003c74010aRCRD.

SEBRAE Nacional. (2018a). O que é o SEBRAE? Recuperado em 28 mai 2018 de http://www.SEBRAE.com.br/sites/PortalSEBRAE/canais_adicionais/o_que_fazemos..

SEBRAE Nacional. (2018b). Estratégia. 2018b. Recuperado em 21 jun 2018 de https://m.SEBRAE.com.br/sites/PortalSEBRAE/canais_adicionais/conheca_estrategia.

SEBRAE Nacional. (2018c). Programa Nacional da Educação Empreendedora - PNEE. Brasília. $\begin{array}{lllll}\text { Recuperado em } & 01 & \text { mai. } & 2018 & \text { de }\end{array}$ http://www.SEBRAE.com.br/sites/PortalSEBRAE/Programas/programa-nacional-da-educacaoempreendedora-pnee,2c7cd24a8321c 510VgnVCM1000004c00210aRCRD.

Silva, M. A. O. M. da., Gomes, L. F. A. M., \& Correia, M. F. (2009). Cultura e Orientação Empreendedora: uma Pesquisa Comparativa entre Empreendedores em Incubadoras no Brasil e Portugal. Revista de Administração Contemporânea, Curitiba, v. 13, n. 1, art. 4, p. 57-71, Jan./Mar.

Tan, J. (2002). Culture, nation, and entrepreneurial strategic orientations: implications for an emerging economy. Entrepreneurship Theory and Practice, 26(4), 95-111.

\title{
The paper of SEBRAE in the dissemination of entrepreneurial education in the northwest region of Minas Gerais
}

\begin{abstract}
This study aims to highlight the role of SEBRAE's Entrepreneurial Education Program, as well as its positive points, highlighting the need for the rise of this type of education for economic, social and sustainable growth. This research was delimited in the Northwest Region of Minas Gerais, through the analysis of the Entrepreneurial Education Radar for Educational Institutions, a tool with attributes that allows to determine the degree of implementation of the Program. Thus, three feedback from schools in the cities of Arinos were made available. Paracatu and Unai of the three types of degrees of implementation, being high, medium and low in order to analyze the different types. The research is classified as bibliographic, qualitative approach, explanatory purpose and documentary instrument. Data were analyzed through content analysis. The relevance of the results lies in the actions of each dimension forming the Entrepreneurial Education ecosystem and the engagement of all. In the actors dimension, it highlights the importance of the teacher's role as one of the main agents of transformation. It also emphasizes the school's participation as a supporter, supporter and incentive of this program. Resources and structures also directly influence the implementation of the entrepreneurial ecosystem in schools. In training the agents involved in the program, SEBRAE plays its role as a transformation agent in the dissemination of the Entrepreneurial Culture and its positive results, highlighting the ways to maintain the program.
\end{abstract}

Keywords: Entrepreneurial Education. SEBRAE. Entrepreneurship. 
Sobre os Autores

\section{Amanda Caroline Faria ALVES}

Graduada em Administração pela Faculdade CNEC Unaí (MG).

Rua Celina Lisboa Frederico, 142, Centro, Unaí, MG, Brasil, CEP 38610-041.

E-mail: amanda.caroolline@hotmail.com

\section{Gevair CAMPOS}

Professor no curso de Administração da Faculdade CNEC Unaí (MG). Mestre em Agronegócios pela Universidade de Brasília (UnB).

Rua Celina Lisboa Frederico, 142, Centro, Unaí, MG, Brasil, CEP 38610-041.

E-mail: javas1989@gmail.com 